\title{
Experimental visualization of oxide-ion diffusion paths in pyrochlore-type $\mathrm{Yb}_{2} \mathrm{Ti}_{2} \mathrm{O}_{7}$
}

\author{
Wataru UNO ${ }^{1}$, Kotaro FUJII ${ }^{1}$, Eiki NIWA ${ }^{1}$, Shuki TORII ${ }^{2}$, Ping MIA0 ${ }^{2, \dagger}$, \\ Takashi KAMIYAMA ${ }^{2}$ and Masatomo YASHIMA ${ }^{1, \dagger}$ \\ ${ }^{1}$ Department of Chemistry, School of Science, Tokyo Institute of Technology, \\ 2-12-1-W4-17 0-okayama, Meguro-ku, Tokyo 152-8551, Japan \\ ${ }^{2}$ Neutron Science Laboratory, Institute of Materials Structure Science, High Energy Accelerator Research Organization (KEK), \\ 1-1 Oho, Tsukuba, Ibaraki 305-0801, Japan
}

Crystal structure and neutron scattering length density distribution of a pyrochlore-type ytterbium titanate $\mathrm{Yb}_{2} \mathrm{Ti}_{2} \mathrm{O}_{7}$ have been investigated by in situ neutron powder diffraction measurements at 293 and $1173 \mathrm{~K}$, Rietveld analysis and maximum-entropy method (MEM). In the MEM neutron scattering length density distributions of $\mathrm{Yb}_{2} \mathrm{Ti}_{2} \mathrm{O}_{7}$, the oxide ion $\mathrm{O}_{48 f}$ bonding to $\mathrm{Ti}$ cation was relatively localized at lower temperature of $293 \mathrm{~K}$, while it was largely distributed at a higher temperature of $1173 \mathrm{~K}$. At $1173 \mathrm{~K}$, one oxide-ion diffusion path along the $\langle 110\rangle$ unshared edge of $\mathrm{TiO}_{6}$ octahedron was clearly visualized and the other oxide-ion diffusion path along $\langle 100\rangle$, strictly $\left\langle 2-8 x\left(\mathrm{O}_{48 f}\right)+38 x\left(\mathrm{O}_{48 f}\right)-3\right\rangle$, shared edge of $\mathrm{TiO}_{6}$ octahedron was also indicated. Here $\boldsymbol{x}\left(\mathrm{O}_{48 f}\right)$ is the atomic coordinate $\boldsymbol{x}$ of $\mathrm{O}_{48 f}$ anion. The MEM neutron scattering length density distribution and difference bond valence sum map at $1173 \mathrm{~K}$ strongly suggested that the energy barrier for oxide-ion migration along $\langle\mathbf{1 1 0}\rangle$ directions was lower than that along the $\langle\mathbf{1 0 0}\rangle$ one. Oxide ions three-dimensionally diffuse through both the $\langle 110\rangle$ and $\langle\mathbf{1 0 0}\rangle$ paths across the unit cell.

(c)2018 The Ceramic Society of Japan. All rights reserved.

Key-words : Pyrochlore, Oxide-lon conductor, Neutron diffraction, Rietveld analysis, Maximum-entropy method

\section{Introduction}

Solid oxides with the fluorite-type structure such as zirconia-, ceria- and bismuth oxide-based materials are fast oxide-ion conductors, which enables the use as electrolyte materials for applications to solid oxide fuel cells and gas sensors. To develop better electrolyte materials requires a better understanding of the ion conduction mechanism, and crucial to this is the knowledge of the diffusion paths of mobile ions at high temperatures where the materials work efficiently. Therefore, the structural disorder and oxide-ion diffusion path of fluorite-type and distorted fluorite-type materials have been studied by numerous researchers. ${ }^{1)-9)}$ These materials exhibit curved diffusion paths along the $\langle 100\rangle$ directions. ${ }^{3), 5)-7), 9)}$

The crystal structure of the $F d \overline{3} m$ pyrochlore-type oxides $A_{2} B_{2} \mathrm{O}_{7}$ can be regarded as a "vacancy-ordered fluorite-type

Corresponding author: M. Yashima; E-mail: yashima@ cms.titech.ac.jp

i† Present address: Department of Physics \& Astronomy, Texas A\&M University, College Station, Texas, 77843, United States

$t+\dagger$ Preface for this article: Dol http://doi.org/10.2109/ jcersj2.126.P5-1 structure" where $A$ is a larger cation as $\mathrm{Yb}^{3+}$ and $\mathrm{Gd}^{3+}$ and $B$ is smaller cation as $\mathrm{Ti}^{4+}, \mathrm{Zr}^{4+}, \mathrm{Hf}^{4+}$. Since some of the $F d \overline{3} m$ pyrochlore-type oxides exhibit high oxide-ion conductivity, ${ }^{10)-13)}$ their crystal structures and oxide-ion conduction mechanism have extensively been studied by X-ray and neutron diffraction experiments, ${ }^{1), 11)-22)}$ and by computational calculations. ${ }^{21), 23)-32)}$ However, there have been no reports on the experimental visualization of oxideion diffusion pathways in pyrochlore-type oxides. The purpose of this work is the experimental visualization of oxide-ion diffusion paths in pyrochlore-type $\mathrm{Yb}_{2} \mathrm{Ti}_{2} \mathrm{O}_{7}$. We have chosen the chemical composition $\mathrm{Yb}_{2} \mathrm{Ti}_{2} \mathrm{O}_{7}$, because $\mathrm{Yb}_{2} \mathrm{Ti}_{2} \mathrm{O}_{7}$ is one of the highest oxide-ion conductors with the pyrochlore-type structure. ${ }^{13)}$ In this work, we apply time-of-flight (TOF) neutron diffraction ${ }^{33)}$ and maximumentropy method ${ }^{3), 5)-7), 34)}$ to study the oxide-ion diffusion paths of $\mathrm{Yb}_{2} \mathrm{Ti}_{2} \mathrm{O}_{7}$. TOF neutron diffraction allows wide $d$ range data to be measured, leading to precise structural parameters and neutron scattering length density distribution, ${ }^{35)}$ thus, we are able to visualize the oxide-ion diffusion pathways in oxide-ion conductors.

\section{Methods}

$\mathrm{Yb}_{2} \mathrm{Ti}_{2} \mathrm{O}_{7}$ sample was synthesized by solid-state reactions. Starting materials of $\mathrm{Yb}_{2} \mathrm{O}_{3}$ (>99.9\% purity) and 
$\mathrm{TiO}_{2}$ (>99.9\% purity) in a molar ratio of $1: 2$ were mixed and ground as dried powders and as ethanol slurries using an agate mortar for $30 \mathrm{~min}$. The mixture was calcined in air at $1273 \mathrm{~K}$ for $12 \mathrm{~h}$. The calcined material was crushed in a tungsten carbide mortar and ground by the agate mortar for $30 \mathrm{~min}$. Obtained powders were pressed into pellets at $130 \mathrm{MPa}$ and sintered in air at $1673 \mathrm{~K}$ for $24 \mathrm{~h}$. White polycrystalline pellets of $\mathrm{Yb}_{2} \mathrm{Ti}_{2} \mathrm{O}_{7}$ were obtained (Size: $8.4 \mathrm{~mm}$ in diameter, $42 \mathrm{~mm}$ in height, Density: 5.34 $\mathrm{g} \mathrm{cm}^{-3}$ ). The chemical composition of $\mathrm{Yb}_{2} \mathrm{Ti}_{2} \mathrm{O}_{7}$ sample was confirmed to be $\mathrm{Yb}: \mathrm{Ti}=2.007(12): 1.993(10)$ by inductively coupled plasma optical emission spectroscopy (ICP-OES), which agreed well with the nominal composition $\mathrm{Yb}_{2} \mathrm{Ti}_{2} \mathrm{O}_{7}$. Thermogravimetric (TG) analyses of $\mathrm{Yb}_{2} \mathrm{Ti}_{2} \mathrm{O}_{7}$ were carried out in air and under $\mathrm{Ar}$ flow between 373 and $1173 \mathrm{~K}$ at the heating and cooling rates of $10 \mathrm{~K} \mathrm{~min}^{-1}$. The TG measurement was repeated three times to confirm the reproducibility and to negate the influence of absorbed species such as water. The TG results in the second and third heating/cooling processes indicated no significant weight change between 373 and $1173 \mathrm{~K}$. Thus, the oxygen content was constant and no additional oxygen vacancies were formed in $\mathrm{Yb}_{2} \mathrm{Ti}_{2} \mathrm{O}_{7}$ at high temperatures.

TOF neutron powder diffraction data of $\mathrm{Yb}_{2} \mathrm{Ti}_{2} \mathrm{O}_{7}$ pellets were measured at 293 and $1173 \mathrm{~K}$. The neutron data were taken using the super-high-resolution diffractometer SuperHRPD ${ }^{33}$ ) installed at the beam line BL-08 of the Materials and Life Science Experimental Facility of the J-PARC center of KEK/JAEA, Tokai, Japan. Rietveld refinements of $\mathrm{Yb}_{2} \mathrm{Ti}_{2} \mathrm{O}_{7}$ were carried out using the neutron data taken by the backscattering bank of SuperHRPD ( $d=0.58-4.0 \AA$ ) with computer program Z-code. ${ }^{36)}$ The absorption correction was performed through the Lobanov empirical formula, ${ }^{35), 37)}$ which is effective to determine accurately the structural parameters and structure factors leading to precise neutron scattering length density distribution.

In order to obtain the neutron scattering length density distribution of $\mathrm{Yb}_{2} \mathrm{Ti}_{2} \mathrm{O}_{7}, \mathrm{MEM}$ analysis was performed based on the neutron diffraction data. MEM analysis was carried out using 0th-order single pixel approximation ${ }^{38)}$ with computer program Dysnomia. ${ }^{39)}$ The observed structure factors $F_{\text {obs }}(d=0.7-4.0 \AA)$ obtained by the Rietveld refinement were used for the MEM analysis with $96 \times$ $96 \times 96$ pixels

Difference bond valence sum (DBVS) |BVS - 2| map of a test oxide ion was calculated for the refined crystal structure of $\mathrm{Yb}_{2} \mathrm{Ti}_{2} \mathrm{O}_{7}$ at $1173 \mathrm{~K}$ with computer program 3DBVSMAPPER. ${ }^{40)}$ Spatial resolution in the calculation of DBVS map was set to $0.1 \AA$. Refined crystal structures, neutron scattering length density distributions and DBVS map of $\mathrm{Yb}_{2} \mathrm{Ti}_{2} \mathrm{O}_{7}$ were depicted with computer program VESTA. ${ }^{41)}$

\section{Results and discussion}

All the reflections in the neutron powder diffraction data of $\mathrm{Yb}_{2} \mathrm{Ti}_{2} \mathrm{O}_{7}$ measured at 293 and $1173 \mathrm{~K}$ were indexed to a face-centered cubic cell, which indicated the sample to be a single cubic phase at these temperatures. Thus, Rietveld refinements of $\mathrm{Yb}_{2} \mathrm{Ti}_{2} \mathrm{O}_{7}$ were carried out by a cubic pyrochlore-type structure (space group: $F d \overline{3} m$ ). In preliminary analyses, it was confirmed that the occupancy factors of $\mathrm{Yb}$ atom at the $16 c$ and $16 d$ sites were 1.00 and 0.00 , respectively, $g(\mathrm{Yb} ; 16 c)=1.00$ and $g(\mathrm{Yb} ; 16 d)=$ 0.00 at 293 and $1173 \mathrm{~K}$, and that the occupancy factors of Ti atom were $g(\mathrm{Ti} ; 16 c)=0.00$ and $g(\mathrm{Ti} ; 16 d)=1.00$ at these temperatures. Thus, there was no $\mathrm{Yb} / \mathrm{Ti}$ occupational disordering at the $16 c$ and $16 d$ sites at these temperatures. In other preliminary Rietveld analyses, the refined occupancy factors of oxygen atom were $g(\mathrm{O} ; 8 a)=1.008(2)$, $g(\mathrm{O} ; 48 f)=1.0033(11)$ and $g(\mathrm{O} ; 8 b)=-0.0005(2)$ at $293 \mathrm{~K}$ and $g(\mathrm{O} ; 8 a)=1.0105(14), g(\mathrm{O} ; 48 f)=1.0030(8)$ and $g(O ; 8 b)=-0.0005(2)$ at $1173 \mathrm{~K}$. Thus, there were no interstitial oxygens at the interstitial $8 b$ site at these temperatures. Similarly, there existed no interstitial oxygens at the $32 e$ site $(1 / 4,1 / 4,1 / 4)$ at these temperatures. In the final refinements, all the occupancy factors were fixed as shown in Table 1. Figure 1 shows the Rietveld patterns of $\mathrm{Yb}_{2} \mathrm{Ti}_{2} \mathrm{O}_{7}$ at 293 and $1173 \mathrm{~K}$, which indicates that the observed intensities agree well with the calculated ones. Table 1 lists the refined crystal parameters and reliability factors in the final Rietveld refinements. The refined lattice parameter of $\mathrm{Yb}_{2} \mathrm{Ti}_{2} \mathrm{O}_{7}$ was $10.034410(4) \AA$ at $293 \mathrm{~K}$, which agree well with the literature value. $\left.{ }^{20}\right)$ The refined atomic coordinate $x$ of oxygen atom at the $48 f$ site, $x\left(\mathrm{O}_{48 f}\right)$ at $293 \mathrm{~K}$ also agrees with the literature value. ${ }^{19)}$ Using the bond valence parameters of Brese and O'Keeffe, ${ }^{42)}$ the bond valence sums (BVSs) of $\mathrm{Yb}^{3+}$ and $\mathrm{Ti}^{4+}$ cations in $\mathrm{Yb}_{2} \mathrm{Ti}_{2} \mathrm{O}_{7}$ at $293 \mathrm{~K}$ were estimated to be 2.90 and 4.14 , which agreed well with the formal charges 3 of $\mathrm{Yb}^{3+}$ and 4 of $\mathrm{Ti}^{4+}$, respectively. These results indicate the validity of the refined crystal structure of $\mathrm{Yb}_{2} \mathrm{Ti}_{2} \mathrm{O}_{7}$.

The lattice parameter of $\mathrm{Yb}_{2} \mathrm{Ti}_{2} \mathrm{O}_{7}$ at $1173 \mathrm{~K}$, $10.133798(2) \AA$ was higher than that at $293 \mathrm{~K}$, 10.034410 (4) $\AA$, due to the thermal expansion. The equivalent isotropic and isotropic atomic displacement parameters $U_{\text {eq }}$ and $U_{\text {iso }}$ of $\mathrm{Yb}_{2} \mathrm{Ti}_{2} \mathrm{O}_{7}$ at $1173 \mathrm{~K}$ were higher than those at $293 \mathrm{~K}$ (Table 1), which indicates larger thermal motion at the higher temperature of $1173 \mathrm{~K}$. Equivalent isotropic atomic displacement parameters of $\mathrm{O}_{48 f}$, $U_{\text {eq }}\left(\mathrm{O}_{48 f}\right)$ was higher than the isotropic atomic displacement parameters of $\mathrm{O}_{8 a} U_{\text {iso }}\left(\mathrm{O}_{8 a}\right)$ at each temperature, $U_{\text {eq }}\left(\mathrm{O}_{48 f}\right)>U_{\text {iso }}\left(\mathrm{O}_{8 a}\right)$. Therefore, the $\mathrm{O}_{48 f}$ exhibits larger thermal motion and positional disorder than $\mathrm{O}_{8 a}$.

Figures 2(a) and 3(a) show the refined crystal structure of $\mathrm{Yb}_{2} \mathrm{Ti}_{2} \mathrm{O}_{7}$ at $1173 \mathrm{~K}$. The structure consists of $\mathrm{Ti}\left(\mathrm{O}_{48 f}\right)_{6}$ octahedra, $\mathrm{O}_{8 a}$ anions and $\mathrm{Yb}$ cations [Figs. 2(a) and 3(a)]. The $\mathrm{O}_{48 f}$ exhibited highly anisotropic atomic displacements in the directions perpendicular to the $\mathrm{Ti}-\mathrm{O}_{48 f}$ bond, which is consistent with the DBVS map [Fig. 2(c)]. Similar anisotropic atomic displacements were reported for pyrochlore-type and perovskite-type oxide-ion conductors. ${ }^{1), 43)-46)}$

In the MEM neutron scattering length density distributions of $\mathrm{Yb}_{2} \mathrm{Ti}_{2} \mathrm{O}_{7}$, no significant densities existed at the 
Table 1. Refined crystal parameters and reliability factors in Rietveld refinement of TOF neutron powder diffraction data (Fig. 1) of $\mathrm{Yb}_{2} \mathrm{Ti}_{2} \mathrm{O}_{7}$ measured at 293 and $1173 \mathrm{~K}^{a}$

\begin{tabular}{lccc}
\hline Composition and temperature & & $\mathrm{Yb}_{2} \mathrm{Ti}_{2} \mathrm{O}_{7}$ at $293 \mathrm{~K}$ & $\mathrm{Yb}_{2} \mathrm{Ti}_{2} \mathrm{O}_{7}$ at $1173 \mathrm{~K}$ \\
\hline Lattice parameter & $a / \AA$ & $10.034410(4)$ & $10.133798(2)$ \\
$\mathrm{Yb}$ at $16 c(0,0,0)$ & $U_{i j} / \AA^{2}$ & $U_{11}=U_{22}=U_{33}=0.00782(6)$ & $U_{11}=U_{22}=U_{33}=0.02743(8)$ \\
& & $U_{12}=U_{13}=U_{23}=-0.00232(7)$ & $U_{12}=U_{13}=U_{23}=-0.00813(8)$ \\
& $U_{\text {eq }} / \AA^{2}$ & $0.00782(6)$ & $0.02743(8)$ \\
& $\mathrm{BVS} / \mathrm{vu}$ & 2.90 & 2.74 \\
& $U_{i j} / \AA^{2}$ & $U_{11}=U_{22}=U_{33}=0.00471(14)$ & $U_{11}=U_{22}=U_{33}=0.01618(16)$ \\
& & $U_{12}=U_{13}=U_{23}=0.0004(2)$ & $U_{12}=U_{13}=U_{23}=0.0005(3)$ \\
& $U_{\mathrm{eq}} / \AA^{2}$ & $0.00471(14)$ & $0.01618(16)$ \\
& $\mathrm{BVS} / \mathrm{vu}$ & 4.14 & 3.98 \\
$\mathrm{O}_{8 a}:$ O at $8 a(1 / 8,1 / 8,1 / 8)$ & $U_{\text {iso }} / \AA^{2}$ & $0.00502(13)$ & $0.01583(14)$ \\
$\mathrm{O}_{48 f}:$ O at $48 f(x, 1 / 8,1 / 8)$ & $x$ & $0.41898(3)$ & $0.42000(3)$ \\
& $U_{i j} / \AA^{2}$ & $U_{11}=0.00804(15)$ & $U_{11}=0.03037(18)$ \\
& & $U_{22}=U_{33}=0.00585(10)$ & $U_{22}=U_{33}=0.02174(10)$ \\
& & $U_{12}=U_{13}=0$ & $U_{12}=U_{13}=0$ \\
& $U_{\text {eq }} / \AA^{2}$ & $U_{23}=-0.00310(13)$ & $U_{23}=-0.01081(14)$ \\
Reliability factors & & $0.00658(6)$ & $0.02462(7)$ \\
& & $R_{\mathrm{wp}}=5.37 \%, R_{\mathrm{p}}=4.34 \%$ & $R_{\mathrm{wp}}=2.43 \%, R_{\mathrm{p}}=1.93 \%$ \\
& $R_{\mathrm{B}}=1.77 \%$ & $R_{\mathrm{B}}=2.08 \%$ \\
\hline
\end{tabular}

${ }^{a}$ Space group: $F d \overline{3} m . g(\mathrm{Yb} ; 16 c)$ : Occupancy factor of $\mathrm{Yb}$ atom at the $16 c$ site. $g(\mathrm{Ti} ; 16 d)$ : occupancy factor of Ti atom at the $16 d$ site. $g(\mathrm{O} ; 8 a)$ : occupancy factor of $\mathrm{O}$ atom at the $8 a$ site. $g(\mathrm{O} ; 48 f)$ : occupancy factor of $\mathrm{O}$ atom at the $48 f$ site. These occupancy factors were fixed to unity: $g(\mathrm{Yb} ; 16 c)=g(\mathrm{Ti} ; 16 d)=g(\mathrm{O} ; 8 a)=g(\mathrm{O} ; 48 f)=1$, in the final refinements.

(a)

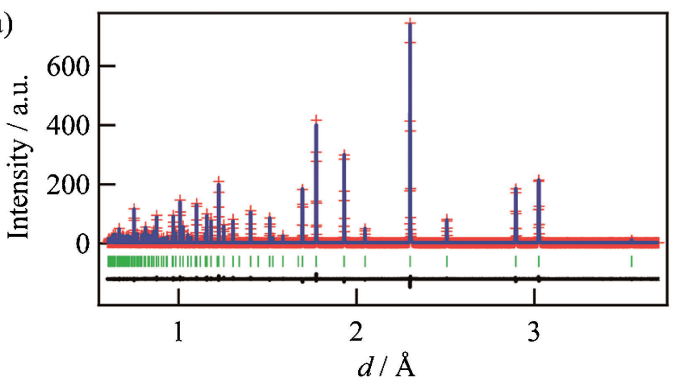

(b)

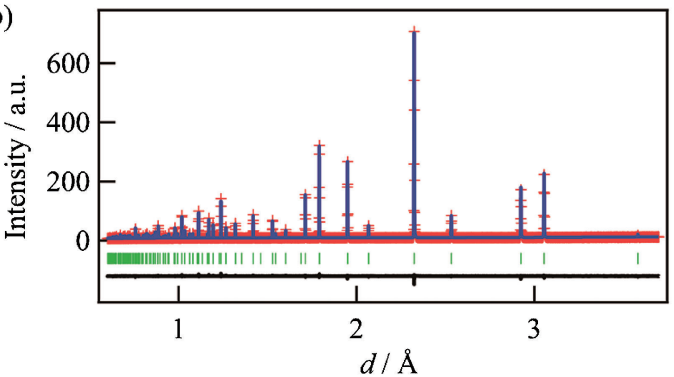

Fig. 1. Rietveld patterns for TOF neutron powder diffraction data of $\mathrm{Yb}_{2} \mathrm{Ti}_{2} \mathrm{O}_{7}$ measured at (a) $293 \mathrm{~K}$ and (b) $1173 \mathrm{~K}$. Red cross and blue line denote observed and calculated intensities, respectively. Green mark stands for the Bragg peak position of a face-centered cubic cell. Black line below the profile denotes the difference pattern.

vacant $8 b$ site at 293 and $1173 \mathrm{~K}$ [Figs. S1 and S2 in the Supporting Information (SI)], which strongly suggests that the $8 b$ site little contributes to the oxide-ion diffusion. The $\mathrm{O}_{8 a}$ was localized and isolated at these temperatures (Figs. $\mathrm{S} 1$ and $\mathrm{S} 2$ in $\mathrm{SI}$ ), which indicates that the $\mathrm{O}_{8 a}$ also little contributes to the oxide-ion diffusion. On the contrary, the $\mathrm{O}_{48 f}$ oxide ion bonding to a Ti cation had much larger spatial distribution at the higher temperature $1173 \mathrm{~K}$ [Fig. 2(d)]. The larger distribution at $1173 \mathrm{~K}$ [Fig. 2(d)] compared with that at $293 \mathrm{~K}$ [Fig. 2(b)] is consistent with (a)

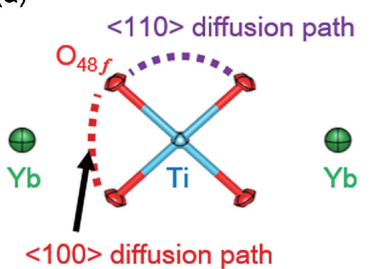

(c)

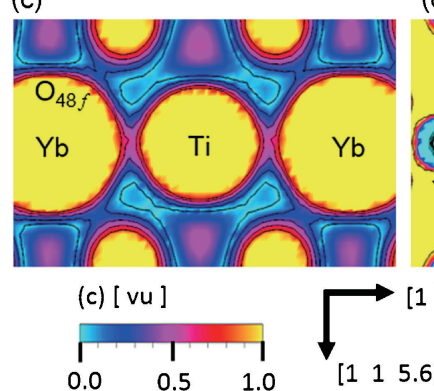

(b)

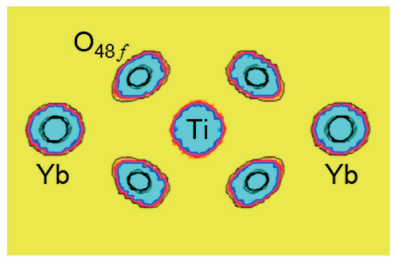

(d)

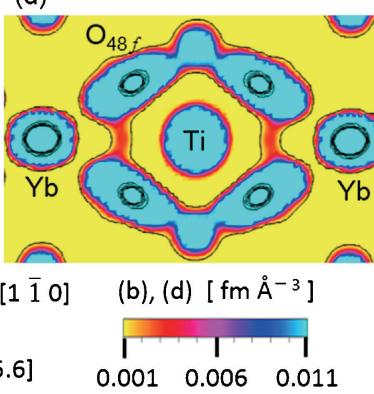

Fig. 2. (a) A part of refined crystal structure on the (2.8 2.8 1) plane of $\mathrm{Yb}_{2} \mathrm{Ti}_{2} \mathrm{O}_{7}$ at $1173 \mathrm{~K}$. Neutron scattering length density distributions on the (2.8 2.8 $\overline{1}$ ) plane of $\mathrm{Yb}_{2} \mathrm{Ti}_{2} \mathrm{O}_{7}$ at $293 \mathrm{~K}$ (b) and $1173 \mathrm{~K}$ (d). (c) Difference bond valence sum (DBVS) map for an oxide ion on the $\left(\begin{array}{lll}2.8 & 2.8 \overline{1}\end{array}\right)$ plane of $\mathrm{Yb}_{2} \mathrm{Ti}_{2} \mathrm{O}_{7}$, which was calculated for the refined crystal structure using the neutron data taken at $1173 \mathrm{~K} . \mathrm{O}_{48 f}$ stands for an oxygen atom at $48 f$ site. Thermal ellipsoids in panel (a) are drawn at $50 \%$ probability level. Contour lines in panels (b) and (d): 0.001 to $50.001 \mathrm{fm}^{-3}$ by $10 \mathrm{fm} \AA^{-3}$ steps. Contour lines in the panel (c): 0.0 to $1.0 \mathrm{vu}$ by $0.2 \mathrm{vu}$ steps.

higher oxide-ion ion conductivity at a higher temperature. ${ }^{16)}$ It should be noted that there existed a connected density distribution between the second nearest neighbor $\mathrm{O}_{48 f}$ anions in the $\langle 110\rangle$ direction, which clearly indicated the oxide-ion diffusion path in $\mathrm{Yb}_{2} \mathrm{Ti}_{2} \mathrm{O}_{7}$. Figure 2(d) strongly suggests the other oxide-ion diffusion path between the nearest neighbor $\mathrm{O}_{48 f}$ and $\mathrm{O}_{48 f}$ anions in the 


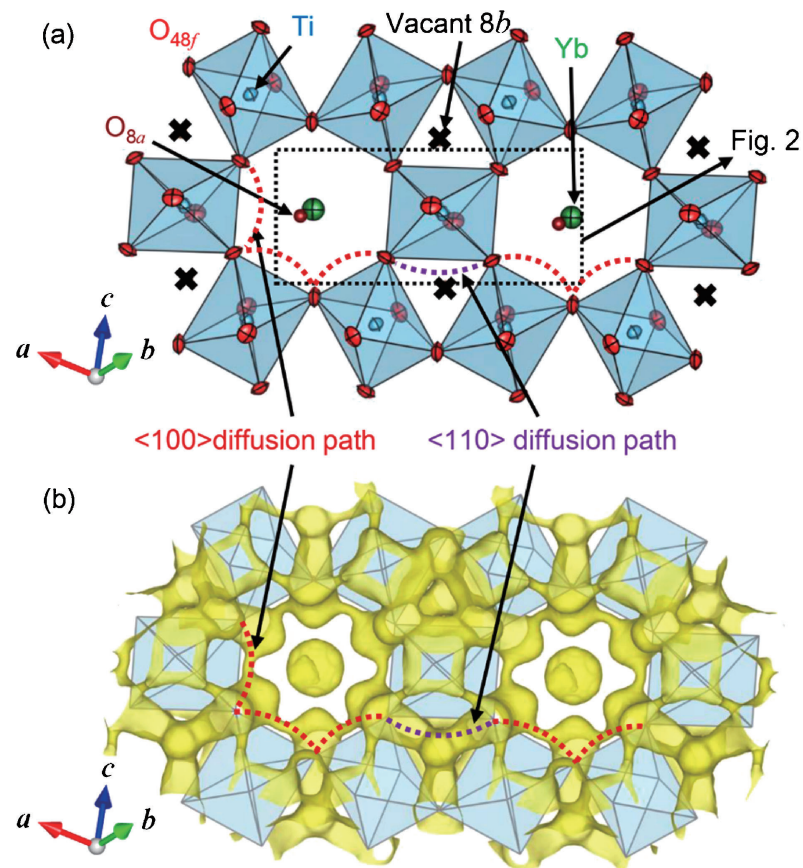

Fig. 3. (a) A part of the refined crystal structure and (b) equidensity surface of the MEM neutron scattering length density distribution of $\mathrm{Yb}_{2} \mathrm{Ti}_{2} \mathrm{O}_{7}$ at $1173 \mathrm{~K}$ at $0.002 \mathrm{fm}^{-3}$.

$\langle 100\rangle$ direction of $\mathrm{Yb}_{2} \mathrm{Ti}_{2} \mathrm{O}_{7}$. Here the exact direction of $\langle 100\rangle$ is $\left[\begin{array}{lll}1 & 1 & 5.6\end{array}\right]=\left[8 x\left(\mathrm{O}_{48 f}\right)-38 x\left(\mathrm{O}_{48 f}\right)-32\right]$ in Fig. 2. The minimum neutron scattering length density on the $\langle 110\rangle$ diffusion path $\left(0.056 \mathrm{fm}^{-3}\right)$ of $\mathrm{Yb}_{2} \mathrm{Ti}_{2} \mathrm{O}_{7}$ was much higher than that on the $\langle 100\rangle$ one $\left(0.003 \mathrm{fm}^{-3}\right)$. Therefore, it is suggested that the energy barrier for oxideion migration along the $\langle 110\rangle$ path was lower than that along the $\langle 100\rangle$ one in $\mathrm{Yb}_{2} \mathrm{Ti}_{2} \mathrm{O}_{7}$. The $\langle 110\rangle$ and $\langle 100\rangle$ diffusion paths in Figs. 2(d) and 3(b) are the first examples of experimental visualization of oxide-ion diffusion in pyrochlore-type oxides. The $\langle 110\rangle$ and $\langle 100\rangle$ diffusion paths were supported also by the DBVS map [Fig. 2(c)]: the maximum DBVS along $\langle 110\rangle(0.10 \mathrm{vu})$ was much lower than that along $\langle 100\rangle(0.51 \mathrm{vu})$ in $\mathrm{Yb}_{2} \mathrm{Ti}_{2} \mathrm{O}_{7}$. An important question is why the $\langle 110\rangle$ path has lower energy barrier compared with $\langle 100\rangle$ one. The $\langle 110\rangle$ path is along the unshared edge between the $\mathrm{Ti}$ and vacant $8 b$ sites, while the $\langle 100\rangle$ path is along the shared edge between the $\mathrm{Ti}$ and $\mathrm{Yb}$ cations. Therefore, the $\langle 110\rangle$ path has lower energy barrier comparing with the $\langle 100\rangle$ one. Figure $3(\mathrm{~b})$ shows the equi-density surface of MEM neutron scattering length density distribution of $\mathrm{Yb}_{2} \mathrm{Ti}_{2} \mathrm{O}_{7}$, which indicates the long-range diffusion paths across the unit cell. An oxide ion in $\mathrm{Yb}_{2} \mathrm{Ti}_{2} \mathrm{O}_{7}$ is able to migrate in the $\langle 100\rangle$ directions through both $\langle 110\rangle$ and $\langle 100\rangle$ diffusion paths across the unit cell. Thus, the pyrochlore-type $\mathrm{Yb}_{2} \mathrm{Ti}_{2} \mathrm{O}_{7}$ exhibits the three-dimensional network of oxide-ion diffusion paths.

\section{Conclusions}

In this work, we have demonstrated the first example of experimental visualization of oxide-ion diffusion paths of the pyrochlore-type oxide-ion conductor. The combined technique of in situ TOF neutron powder diffraction measurements at high temperatures and maximum-entropy method enabled to obtain reliable neutron scattering length density distribution, indicating the experimental oxide-ion diffusion pathways. It was found that there exist two kinds of oxide-ion diffusion paths along $\langle 110\rangle$ and $\langle 100\rangle$ (strictly, $\left.\left\langle 2-8 x\left(\mathrm{O}_{48 f}\right)+38 x\left(\mathrm{O}_{48 f}\right)-3\right\rangle\right)$ directions. The minimum neutron scattering length density on the $\langle 110\rangle$ path was higher than that on $\langle 100\rangle$, and DBVS on the $\langle 110\rangle$ was lower than DBVS on $\langle 100\rangle$. These results strongly suggest that the energy barrier for $\langle 110\rangle$ oxide-ion migration is lower than that for $\langle 100\rangle$. Furthermore the present study has clearly indicated that an oxide ion three-dimensionally diffuses through both the $\langle 100\rangle$ and $\langle 110\rangle$ paths.

Acknowledgment The neutron diffraction measurements by SuperHRPD were performed with the approval (2013B0198, 2014B0233, 2015A0190, 2016A0175, 2017A0111, 2017L1300). The ICP-OES analyses were kindly performed by Daiichi-Kigenso Co. This study was partly supported by a Grant-in-Aid for Scientific Research (KAKENHI, Nos. JP15H02291, JP25630365, JP26870190, JP16H00884, JP16H06293，JP16H06440，JP16H06438，JP16H06438, JP17H06222) from the Ministry of Education, Culture, Sports, Science and Technology of Japan, and JSPS Coreto-Core Program, A. Advanced Research Networks (Solid Oxide Interfaces for Faster Ion Transport).

\section{Reference}

1) T. Moriga, A. Yoshiasa, F. Kanamaru, K. Koto, M. Yoshimura and S. Somiya, Solid State Ionics, 31, 319328 (1989).

2) J. C. Boivin and G. Mairesse, Chem. Mater, 10, 28702888 (1998).

3) M. Yashima and D. Ishimura, Chem. Phys. Lett., 378, 395-399 (2003).

4) S. Hull, Rep. Prog. Phys., 67, 1233-1314 (2004).

5) M. Yashima and D. Ishimura, Appl. Phys. Lett., 87, 221909 (2005).

6) M. Yashima, S. Kobayashi and T. Yasui, Faraday Discuss., 134, 369-376 (2007).

7) M. Yashima, J. Ceram. Soc. Jpn., 117, 1055-1059 (2009).

8) A. Orera and P. R. Slater, Chem. Mater, 22, 675-690 (2010).

9) M. Yashima, Catal. Today, 253, 3-19 (2015).

10) M. P. van Dijk, K. J. de Vries and A. J. Burggraaf, Solid State Ionics, 9, 913-919 (1980).

11) B. J. Wuensch, K. W. Eberman, C. Heremans, E. M. Ku, P. Onnerud, E. M. Yeo, S. M. Haile, J. K. Stalick and J. D. Jorgensen, Solid State Ionics, 129, 111-133 (2000).

12) H. Yamamura, H. Nishino, K. Kakinuma and K. Nomura, Solid State Ionics, 158, 359-365 (2003).

13) A. V. Shlyakhtina and L. G. Shcherbakova, Russ. J. Electrochem., 48, 1-25 (2012).

14) O. Knop, F. Brisse and L. Castelliz, Can. J. Chem., 47, 971-990 (1969).

15) M. A. Subramanian, G. Aravamudan and G. V. Subba Rao, Prog. Solid State Ch., 15, 55-143 (1983). 
16) A. V. Shlyakhtina, P. Fedtke, A. Busch, I. V. Kolbanev, T. Barfels, M. Wienecke, A. E. Sokolov, V. A. Ulianov, V. A. Trounov and L. G. Shcherbakova, Solid State Ionics, 179, 1004-1008 (2008).

17) T. Hagiwara, H. Yamamura and H. Nishino, IOP Conf. Ser.: Mater. Sci. Eng., 18, 132003 (2011).

18) K. A. Ross, T. Proffen, H. A. Dabkowska, J. A. Quilliam, L. R. Yaraskavitch, J. B. Kycia and B. D. Gaulin, Phys. Rev. B, 86, 174424 (2012).

19) J. M. Farmer, L. A. Boatner, B. C. Chakoumakos, M.-H. Du, M. J. Lance, C. J. Rawn and J. C. Bryan, J. Alloy. Compd., 605, 63-70 (2014).

20) K. Baroudi, B. D. Gaulin, S. H. Lapidus, J. Gaudet and R. J. Cava, Phys. Rev. B, 92, 24110 (2015).

21) K. Nakamura, M. Mori, T. Itoh and T. Ohnuma, AIP Adv., 6, 115003 (2016).

22) T. Hagiwara, K. Nomura and H. Kageyama, J. Ceram. Soc. Jpn., 125, 65-70 (2017).

23) M. P. van Dijk, A. J. Burggraaf, A. N. Cormack and C. R. A. Catlow, Solid State Ionics, 17, 159-167 (1985).

24) P. J. Wilde and C. R. A. Catlow, Solid State Ionics, 112, 173-183 (1998).

25) M. Pirzada, R. W. Grimes, L. Minervini, J. F. Maguire and K. E. Sickafus, Solid State Ionics, 140, 201-208 (2001).

26) C. R. Stanek, L. Minervini and R. W. Grimes, J. Am. Ceram. Soc., 85, 2792-2798 (2002).

27) M. Pirzada, R. W. Grimes and J. F. Maguire, Solid State Ionics, 161, 81-91 (2003).

28) W. R. Panero, L. Stixrude and R. C. Ewing, Phys. Rev. $B, 70,54110$ (2004).

29) H. Y. Xiao, X. T. Zu, F. Gao and W. J. Weber, J. Appl. Phys., 104, 73503 (2008).

30) J. Wang, F. Zhang, J. Lian, R. C. Ewing and U. Becker, Acta. Mater., 59, 1607-1618 (2011).

31) X. J. Wang, H. Y. Xiao, X. T. Zu, Y. Zhang and W. J.
Weber, J. Mater. Chem. C, 1, 1665-1673 (2013).

32) H. Y. Xiao, W. J. Weber, Y. Zhang and X. T. Zu, Acta. Mater., 87, 273-282 (2015).

33) S. Torii, M. Yonemura, T. Yulius Surya Panca Putra, J. Zhang, P. Miao, T. Muroya, R. Tomiyasu, T. Morishima, S. Sato, H. Sagehashi, Y. Noda and T. Kamiyama, J. Phys. Soc. Jpn., 80, SB020 (2011).

34) M. Sakata, T. Uno, M. Takata and C. H. Howard, J. Appl. Crystallogr., 26, 159-165 (1993).

35) A. Fujimoto, M. Yashima, K. Fujii and J. R. Hester, J. Phys. Chem. C, 121, 21272-21280 (2017).

36) R. Oishi, M. Yonemura, Y. Nishimaki, S. Torii, A. Hoshikawa, T. Ishigaki, T. Morishima, K. Mori and T. Kamiyama, Nucl. Instrum. Meth. A, 600, 94-96 (2009).

37) N. N. Lobanov and L. Alte da Veiga, 6th Eur. Powder Diffr. Conf. Abstr., (1988) P12-16.

38) M. Kumazawa, M. Takata and M. Sakata, Acta Crystallogr. A, 51, 47-53 (1995).

39) K. Momma, T. Ikeda, A. A. Belik and F. Izumi, Powder Diffr., 28, 184-193 (2013).

40) M. Sale and M. Avdeev, J. Appl. Crystallogr., 45, 1054 1056 (2012).

41) K. Momma and F. Izumi, J. Appl. Crystallogr., 44, 1272-1276 (2011).

42) N. E. Brese and M. O'Keeffe, Acta Crystallogr. B, 47, 192-197 (1991).

43) M. Yashima, K. Nomura, H. Kageyama, Y. Miyazaki, N. Chitose and K. Adachi, Chem. Phys. Lett., 380, 391396 (2003).

44) M. Yashima and T. Tsuji, J. Appl. Crystallogr., 40, 1166-1168 (2007).

45) M. Yashima and T. Kamioka, Solid State Ionics, 179, 1939-1943 (2008).

46) Y.-C. Chen, M. Yashima, T. Ohta, K. Ohoyama and S. Yamamoto, J. Phys. Chem. C, 116, 5246-5254 (2012). 